\title{
The effect of correctional exercises on body image and social anxiety in students with lordosis disorder
}

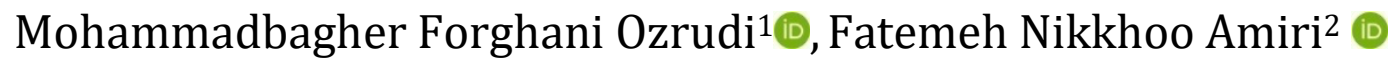

1 Young Researchers and Elite Club, Babol Branch, Islamic Azad University, Babol, Iran. ${ }^{2}$ Pathology and Corrective Exercises, PE Teacher, Education Office, Babol, Iran

\begin{abstract}
The aim of the current research was to examine the effect of 12 weeks of correctional exercises on body image and social anxiety in students with lordosis disorder. Statistical society of research includes boy university students in master's degree level of Mazandaran University of Science and Technology. The research sample includes 30 boy university students and has been selected randomly and voluntarily and has been divided into two groups of test and control. To gather data, we have used multi-dimension relations of a self-body questionnaire and social agitation questionnaire. The method of research is tested in the pre-test, post-test kind, and by the control group. The result of variance analysis showed there is a meaningful difference between experimental group and control group. It means, reforming practices are influential on improving body image and social agitation.
\end{abstract}

Keywords. Body image, correctional exercises, social anxiety, students, lordosis.

\section{Introduction}

Behavior development and learning are concentrated on understanding and internal and external factors influential on knowledge completeness (Krapp et al., 1992). Self-imagination as one of these factors is deterministic on understanding and sensation completeness of a person. Self-imagination is a collection of characteristics in which a person applies for his description and is one of the important aspects of social growth in which has been achieved gradually through social experience and relation to others (Biabangard, 1997).

Self-imagination does have multi-dimensions structure in which could be divided into two levels of educational and non-educational. Educational selfimagination or scientific is related to self-imagination in the grounds of lessons like mathematic, English language. Non-educational self-imagination is divided into a social level, sensation, and body in which any of them does have some dimensions (Marsh \& Roch, 1995; Marsh \& Seeshing, 1997).
Bodily self-imagination or self-description of the body as a one of non-educational self-imagination shows person view to bodily dimension, abilities, bodily skills like body appearance, fat content, flexibility, coordination, stability, power, etc. (Marsh \& Peart, 1988). Body condition and figure structure are related to the body and mental health, existence of figure rudeness does have undesired effects on understanding and body image, especially in youth (Alnabi, 2000). It could influence on person's selfconfidence (Daneshmandi et al., 2019).

Reforming practice as a try for removing body rudeness like back Kyphosis, Scoliosis, back Lordosis through coordination of agreed muscular groups, nonagreement, and by vigor and tension practices. Reforming practice includes tension practice, power, and facilitating nerve-muscular practices (Meyer, 2011). There are so many studies about the spinal column and mental factors. Norris et al. (1992) and Boomgeraphner \& Soker (1990) showed there is a relationship between body condition and mental factors (Goodarzi, 2014). Noonan et al. (1997) showed

\footnotetext{
M. Forghani Ozrudi, e-mail: mohammadbagher.forghani@gmail.com Received: March 03, 2021 - Accepted: August 19, 2021 - Published: October 07, 2021

To Cite: Forghani Ozrudi, M., Amiri, F.N. (2021). The effect of correctional exercises on body image and social anxiety in students with lordosis disorder. Turk J Kinesiol, 7(3), 87-91. DOI: 10.31459/turkjkin.900496
} 
the effect of mental characteristics on those who have spinal column rudeness.

Against Balzini et al, studies in which examined the behavior of persons by spinal column rudeness and showed there is a relation among these variables and spinal column status rudeness (Balzini et al., 2003).

A study on Tehran university students has not found significant relation among Kyphosis mean and mental factors (Asghari, 2006). From a clinical view, agitation in different levels of behavioral, bodily, and understanding has been observed. But, because any agitation mode does have a mental and bodily indicator, therefore, agitation requires some bodily signs (Meyer, 2001).

It has been found in a study, more than $90 \%$ of patients affected by body rudeness have experienced one period of basic depression in their life. About 70\% does have agitation disorder and about 30\% have pilocytic (Mohammad, 2002). Mosburger \& Egel (1991) has done some studies for finding characteristic disorder in a patient affected by spinal column disease and determined all of them do have agitation characteristic and depression (Mosburger \& Egel, 1991).

Balzini et al. (2003) have studied clinical behavior on those who have had body status rudeness. The result showed those who had the more bent figure, do have more depression and lower interest than the groups in which do have a lesser bent figure (Balzini et al., 2003). According to the above-mentioned and less research related to the current topic at global level, the object of this research is to determine the effect of 12 weeks of reforming practice on body self-description and social agitation of university students by Lordosis rudeness in Mazandaran University of Science and Technology. The present study aimed to find out whether 12 weeks of corrective exercises affect body image and social anxiety in students with lordosis disorder.

\section{Methods}

This study has been done in a semi-experimental method. Statistical society of research includes university students which among them, about 30 have participated voluntarily in research (Experimental Group = 15, Control Group = 15). All tastes have completed written satisfaction form informed before participating in the research procedure. The measures for participation were having Kyphosis disorder and converting Lordosis. Also, the participator does not have a record in continuous practice three times in a week for three months and in other cases has been omitted. The study was conducted in accordance with Helsinki Declaration.

\section{Research Tools}

The method of research is to gather two groups of university students in a sports hall and after explaining the object of research and satisfying tastes, body image and social agitation questionnaire has been provided to university students and after completing and returning the questionnaire, the member of experimental group has been obliged to perform Williams reforming practice including tension and power practice for removing rudeness for 12 weeks and every day in two times and control group has done re-creative sport. At last, the two groups have completed questionnaires. Then after gathering information, data has been analyzed by multi-variables analysis method.

In this study, in order to evaluate body selfdescription, we have used multi-dimension self-body, we could use this questionnaire for youth and adults, too. The short form of the questionnaire includes 34 questions by 5 sub-scales: appearance evaluation, looking to appearance, mental occupation by the weight more than limit, understanding weight category, and satisfaction from body areas (Mosburger \& Egel, 1991). In evaluating social agitation, we have used of social agitation questionnaire including 24 questions and for evaluating agitation and avoidance to performance or social situation has been designed (Cash et al., 2004). In evaluating Lordosis rudeness, we have used of spinal column mouse, inner group stability and outer group has shown high in measuring general spinal column bow (Berahmand, 2009). This program on experimental group is collection of Williams's practices. Williams has published a program on reaction to clinical observance for patients by chronic back aches. These sports are for men under 50 years old and women under 40 years old in which does have increases in back Lordosis and decrease in disk space among back spinal and have low aches. The objects of these practices are to decrease aches and making stable under part of body and does have emphasis on back flexion (Mannion et al., 2004; Sanatkaran, 2008; Hematfar \& Sedaghati, 2013; Khanjani et al., 2014). 


\section{Results}

According to Table 1 the Kolmogorov-Smirnov test showed data does have natural distribution $(\mathrm{p}>0.05)$. Therefore, we have used of parametric statistic for analyzing data.

Table 1 presents the mean and standard deviation of the two groups of experimental and control before and after exporting to independent variables. From Table 2, we have the mean of experimental group does have a positive effect after exporting to the independent variable in body image and social agitation. In other words, the body image of experimental group is more positive and the social agitation of university students in this group decreased.

As shown in Table 3, there is a significant difference between experimental group and control group in body image $(\mathrm{F}=19.538 ; \mathrm{p}=0.001)$ and social agitation $(\mathrm{F}=41.327 ; \mathrm{p}=0.001)$. In another word, Williams reforming practices according to the mean in two groups leads to positive body image and decreasing social agitation.

\section{Discussion}

Unfortunately, because the topic of research is not the same as current research and in this section, we have paid to the result of research and don't compare them to the same research, too. In this research, we examined the effect of body image and social agitation in university students. The result showed Williams reforming practices are influential on body image and social agitation in university students.

The result showed reforming practices do have positive effects on self-description and decreasing social agitation. In explaining this finding, we could say: doing reforming movement by establishing better muscular balance and increasing bodily efficiency in peoples by rudeness improves body image and decreases social agitation, too. It avoids non-selfconfidence and inefficiency sensation because of laziness and muscular non movement and at last bad looking of rudeness and non-balance and non-feasible bodily figures and improves body image and self-image and decreases agitation, too. The results of the present study on the effect of corrective movements on improving the condition of people with kyphosis are consistent with the results of Kamali et al. (2018).

Table 1

The result of Kolmogorov-Smirnov test.

\begin{tabular}{lccc}
\hline Demographic Characteristic & Indicator & Social Agitation & Self-Descriptive Body \\
\hline $\mathrm{n}$ & 15 & 15 & 15 \\
$\mathrm{p}$-value & 0.705 & 0.196 & 0.341 \\
\hline
\end{tabular}

Table 2

Body image and social agitation in test and control groups (Mean \pm SD).

\begin{tabular}{lcccc}
\hline \multirow{2}{*}{ Variables } & \multicolumn{2}{c}{ Experimental Group } & \multicolumn{2}{c}{ Control Group } \\
\cline { 2 - 5 } & Pretest & Posttest & Pretest & Posttest \\
\hline Body image & $132.06 \pm 3.59$ & $119.26 \pm 2.81$ & $132.266 \pm 2.65$ & $131.86 \pm 3.68$ \\
Social anxiety & $55.53 \pm 2.09$ & $48.73 \pm 2.37$ & $54.66 \pm 2.63$ & $55.13 \pm 2.29$ \\
\hline
\end{tabular}

Table 3

Variance analysis for body image \& social agitation in experimental test and control groups.

\begin{tabular}{lccccc}
\hline Variables & SS & DF & MS & F & $p$ \\
\hline Body image & 324.02 & 1 & 324.25 & 19.58 & $0.001^{*}$ \\
Social anxiety & 927.00 & 1 & 927.00 & 41.32 & $0.001^{*}$ \\
\hline$* p 0.05$ & & & & &
\end{tabular}


In general, it can be concluded that this anomaly creates problems for the person, and it also endangers the person's health psychologically. Accordingly, it is possible to improve their mental health by encouraging people with disorders to exercise and corrective exercises.

\section{Conclusion}

All mentioned above, are very important in reforming practice on body image. It seems participating in reforming programs does have a medium role in increasing self-esteem and view to itself. Doing reforming movement increases body ability level and body readiness and changes the kind of person's evaluation from his abilities. In general, the current study showed sport improves body image and decreases social agitation, but future research could declare the effects of this kind of practice.

\section{References}

Al-Nabi, S.T. (2000). Evaluation of medical problems in children and adolescents in sport. Research report. Presented at the Second International Congress of Sport School in Tehran. Proceedings of the Second International Congress of print books with an emphasis on sports during elementary school. Publications of Physical Education department. Ministry of Education, Iran.

Asghari, A. (2003). Determines the positional relationship of spine disorders, with depression and anxiety in athletes and non-athletes selected University of Tehran. Master's Thesis, Islamic Azad University, Iran.

Balzini, L., Vannucchi, L., Benvenuti, F., Benucci, M., Monni, M., \& Cappozzo, A. (2003). Clinical characteristics of flexed posture in Elderly women. American Geriatrices Society, 51(10), 1419-1426.

Biabangard, E. (1997). The methods of increasing self-esteem in children and adolescents. 4th ed. Tehran, Iran: Islamic Republic of Iran Guardians and Teachers Society.

Berhmand, 0. (2009). Prevalence of body dysmorphic disorder and psychological factors associated with adolescents and young adults. Research Project, University of Mohaghegh Ardebili, Iran.

Cash, T.F., Theriault, J., \& Milkewicz-Annis, N. (2004). Body image in an interpersonal context: adult attachment, fear of intimacy and social anxiety. Journal of Social and Clinical Psychology, 23(1), 89-103.
Daneshmandi, H., Alizadeh, M.H., \& Gharakhanlou, R. (2019). Corrective exercises. $2^{\text {nd }}$ Ed., Iran: Samt Publisher.

Goodarzi, B. (2014). The influence of 12 weeks reforming practice on body self-descriptive and social agitation of university students. Journal of Applied Science and Agriculture, 9(4), 1988-1991.

Hematfar, A., \& Sedaghati, N. (2013). Comparison of the effects Williams exercise \& Pick a water treatment on pain intensity and lumbar lordosis by female students, Journal of Sports Sciences, 2(8), 21-11

Kamali, A., Shokri, B., Javdaneh, N., \& Ghasemi, B. (2018). The effects of 8 weeks exercise with the Balance ball on the amount of Lordosis of male students 15-18 years old. Journal of Practical Studies of Biosciences in Sport, 5(10), 35-44.

Khanjani, M., Bararzadeh, M., \& Forghani Ozrudi, M.B. (2014). Relaxation practice influence on mood competitive agitation in female karate fighter. International Journal of Sport Studies. 4(1), 67-71.

Krapp, A., Hidi, S., \& Renninger, A. (1992). Interest, learning and development. In: Renninger, A., Hidi, S., Krapp, A. (editors). The role of interest in learning and development. 1st ed. Hillsdsle: Lawrence Erlbaum.

Lo, C.L. (1998). The effects of extra-curricular activities on the self-concept of Taiwanese university students. Master Thesis, University of South Dakota, USA.

Mannion, A.F., Knecht, K., Balaban, G., Dvorak, G., \& Grob, D. (2004). A new skin-surface device for measuring the curvature and global and segmental ranges of motion of the spine: reliability of measurements and comparison with data reviewed from the literature. Eur Spine J, 13, 122-136.

Marsh, H.W., \& Peart, N. (1988). Competitive and cooperative physical fitness training programs for girls: Effects on physical fitness and on multidimensional selfconcepts. J Sport Exerc Psychol, 10, 390-407.

Marsh, H.W., \& Roch, L. (1995). Multidimensional selfconcept of elite athletes: How do they differ from the general populations? J Sport Exerc Psychol, 17, 70-83.

Marsh, H.W., \& Seeshing, Y.A. (1997). Causal effects of academic self-concept on academic achievement. J Edu Psychol, 89, 1041-1054.

Meyer, D.W. (2001). Correction of spondylolisthesis by the correction of global posture. Clinical Chiropractic, 22-23.

Mohammed, S. (2002). Thesis Personality characteristics of patients with ulcerative colitis compared with healthy subjects. Master Thesis, Tehran Psychiatric Institute, Iran.

Mosburger, H., \& Egel, K.S. (1991). Determine of pain Exercise: perceived competence, trait anxiety, trait 
depression and moderate effects. Personality and Individual Differences, 12(12), 1261-1266.

Noonan, K.J., Dolan, L.A., Jacobson, W.C., \& Weinstein, S.L. (1997). Long-term psychosocial characteristics of patients treated for idiopathic scoliosis. J Pediatr Orthop, 17(6), 712-717.

Noonan, K.J., Dolan, L.A., Jacobson, W.C., \& Weinstein, S.L. (1992). The effects of physical activity and exercise training on psychological stress and well-being in an adolescent population. J Psychosom Res, 36, 55-65.
Norris, R., Carroll, D., \& Cochrane, R. (1992). The effects of physical activity and exercise training on psychological stress and well-being in an adolescent population. J Psychosom Res, 36(1), 55-65.

Sanatkaran, A. (2008). Relaxation effects on competitive anxiety - a condition in adolescent wrestlers. Proceedings of the Scientific Conference of Iran, Islamic Azad University, Iran, 119-114. 